\title{
Effects of Silicon on the Microstructure and Mechanical Properties of 15-15Ti Stainless Steel
}

\author{
Hao-Yu Yi ${ }^{1} \cdot$ Tian Liang ${ }^{2} \cdot$ Min Wang $^{2} \cdot$ Xiang-Dong Zha $^{2} \cdot$ Ying-Che $\mathrm{Ma}^{2} \cdot \mathrm{Kui} \mathrm{Liu}^{2}$ \\ Received: 17 December 2019 / Revised: 17 March 2020 / Published online: 3 June 2020 \\ (๑) The Chinese Society for Metals (CSM) and Springer-Verlag GmbH Germany, part of Springer Nature 2020
}

\begin{abstract}
Effects of silicon on the microstructure and mechanical properties of 20\% cold-worked 15-15Ti austenitic stainless steels are systemically investigated by uniaxial tensile tests, scanning and transmission electron microscope observations, and strength calculations. The results reveal that a large number of deformation twins are formed in the $20 \%$ cold-worked steels with various silicon additions. The volume fraction of deformation twins and the density of dislocations increase with silicon content, while the twin thickness slightly decreases. A better strength-ductility combination is achieved by silicon addition, since the yield strength of the steel with $2 \%$ silicon is $61 \mathrm{MPa}$ higher than that of the steel with $1 \%$ silicon, while their uniform elongations are almost both equal to $16 \%$. The yield strength of the 15-15Ti stainless steels is predominantly contributed by the solid solution, dislocation and deformation twin strengthening effects, which can be enhanced by silicon addition.
\end{abstract}

Keywords Austenitic stainless steel $\cdot$ Silicon $\cdot$ Microstructure $\cdot$ Mechanical property

\section{Introduction}

15-15Ti austenitic stainless steels (SSs), a special kind of modified 316Ti SS, are widely used in $20 \%$ cold-worked condition as a cladding and hexagonal duct material for fuel subassemblies of sodium-cooled fast reactors (SFRs) like Phenix [1], thanks to their excellent mechanical properties, good weldability and appropriate irradiation swelling resistance of 77 displacement per atom (dpa) [2,3]. Because of these advantages, nowadays $15-15 \mathrm{Ti}$ SS is under consideration of being selected as a candidate material for the fuel assemblies of lead-cooled fast reactors (LFRs). However, previous work [4] indicated a temperature limit of $500{ }^{\circ} \mathrm{C}$ for SS application in LFR, owing to the serious dissolution

Available online at https://link.springer.com/journal/40195.

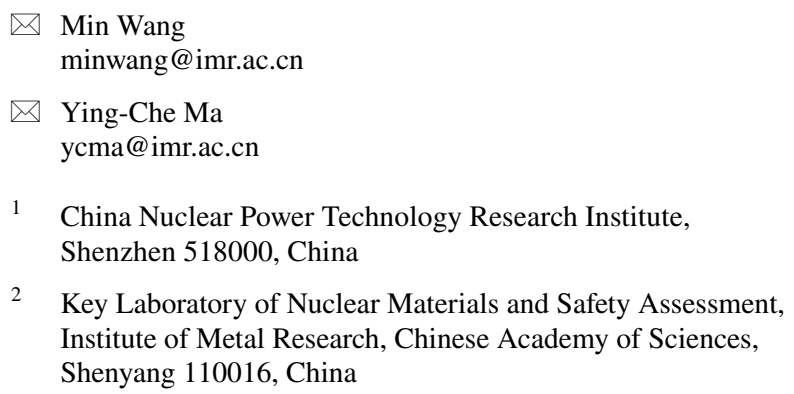

2 Key Laboratory of Nuclear Materials and Safety Assessment, Institute of Metal Research, Chinese Academy of Sciences, Shenyang 110016, China

attack when SS is subjected to the exposure in high-temperature liquid lead for a long term. Furthermore, the irradiation resistance of LFR fuel assembly material needs to be further improved to $150 \mathrm{dpa}$ when considering the possibility of high-burn-up fuel applications [5].

Recent studies showed that the corrosion resistance of stainless steels in liquid lead could be improved by silicon addition [6]. Additionally, silicon is also known as an effective element in increasing irradiation swelling resistance of SSs [7]. Therefore, silicon addition may be an effective way to improve both corrosion and irradiation swelling resistances of 15-15Ti SS. Effects of silicon on the microstructure and mechanical properties of 15-15Ti SS, however, have not been systematically studied yet, to the authors' knowledge. In the present work, three types of 15-15Ti SS (namely R1, R2 and R3) with various silicon contents are fabricated and employed to investigate the effects of silicon on the microstructure and mechanical properties of 15-15Ti SS.

\section{Experimental}

The materials used in this study were produced by the processes of vacuum induction melting (VIM), vacuum arc remelting (VAR), forging, hot rolling, cold rolling and heat treatments. Specifically, at first three VIM ingots with 
various $\mathrm{Si}$ additions were casted and re-melted in a VAR furnace. Ingots were then forged into rectangular plates with a cross section of $50 \mathrm{~mm} \times 110 \mathrm{~mm}$ at $1200{ }^{\circ} \mathrm{C}$. After that, the materials were hot rolled at $1180{ }^{\circ} \mathrm{C}$ to the thickness of $9.5 \mathrm{~mm}$, followed by an annealing treatment at $1100{ }^{\circ} \mathrm{C}$ for $30 \mathrm{~min}$ in a vacuum argon-quenching furnace. Subsequently, the steels were cold rolled to the thickness of $2.5 \mathrm{~mm}$ and annealed at $1045{ }^{\circ} \mathrm{C}$ for $20 \mathrm{~min}$. At last, the materials were cold rolled once again for a $20 \%$ thickness reduction, and the final thickness was about $2.0 \mathrm{~mm}$. Chemical compositions of the $20 \%$ cold-worked stainless steels are listed in Table 1.

Microstructures of the cold-worked 15-15Ti SS samples were characterized by using optical microscopy (OM) on a ZEISS Axio Observer $3 \mathrm{~m}$, scanning electron microscope (SEM) on a ZEISS Gemini, transmission electron microscope (TEM) operated at $200 \mathrm{kV}$ on a FEI G2 F20 and X-ray diffraction (XRD) on a Bruker D8 Advance. For optical microscopic observations, samples were cut parallel to the roll direction (longitudinal), mechanically ground and polished, and then chemically etched using a solution of $5 \mathrm{~g}$ ferric trichloride, $100 \mathrm{~mL}$ hydrochloric acid and 100 $\mathrm{mL}$ water. Longitudinal specimens for SEM and XRD were mechanically polished and electro-etched at ambient temperature with an electrolyte consisting of $8 \%$ perchloric acid and $92 \%$ alcohol. The electro-etched current density was $0.8-1 \mathrm{~A} / \mathrm{cm}^{2}$. Transverse-sectional TEM foils were sliced and thinned to $40 \mu \mathrm{m}$ by grinding. Then, the cross-sectional TEM samples were electro-polished on a double-jet polisher, using an electrolyte consisting of $8 \%$ perchloric acid and $92 \%$ alcohol at about $-15{ }^{\circ} \mathrm{C}$.

Uniaxial tensile tests were performed on an INSTRON 5582 with a strain rate of $1.67 \times 10^{-4} \mathrm{~s}^{-1}$ at ambient temperature. The tensile samples were cut into a dog-bone shape with a gage section of $20 \mathrm{~mm} \times 4.0 \mathrm{~mm} \times 2.0 \mathrm{~mm}$. More than three tests were performed for each data point. The displacement was measured by using the instrument's linear variable differential transformer.

\section{Results}

\subsection{Microstructure of the Cold-Worked 15-15Ti SS}

\subsubsection{OM Characterization of the Cold-Worked 15-15Ti SS}

The OM images in Fig. 1 display similar longitudinal microstructures of the three cold-worked 15-15Ti SS samples. The original grain boundaries are clearly identified, and the average grain sizes of the three samples are $17.7 \pm 1.2 \mu \mathrm{m}$, $17.3 \pm 1.0 \mu \mathrm{m}$ and $20.9 \pm 1.5 \mu \mathrm{m}$, respectively. In addition, inside the grains are numerous parallel deformation twins, some of which intersect with each other. In order to precisely measure the content of deformation twins, we further employed backscattering electron (BSE) imaging in SEM to observe the microstructure. The observation fields were randomly chosen and the magnification was set at $1000 \times$ to cover sufficiently large areas, with the purpose of assuring

Table 1 Chemical compositions of steels investigated (wt $\%$ )

\begin{tabular}{lllllllll}
\hline & $\mathrm{Si}$ & $\mathrm{Ni}$ & $\mathrm{Cr}$ & $\mathrm{Mn}$ & $\mathrm{Ti}$ & $\mathrm{Mo}$ & $\mathrm{C}$ & $\mathrm{Fe}$ \\
\hline $\mathrm{R} 1$ & 1 & 15 & 17 & 1.5 & 0.36 & 1.5 & 0.06 & Bal \\
$\mathrm{R} 2$ & 1.5 & 15 & 17 & 1.5 & 0.36 & 1.5 & 0.06 & Bal \\
$\mathrm{R} 3$ & 2.0 & 15 & 17 & 1.5 & 0.36 & 1.5 & 0.06 & Bal \\
\hline
\end{tabular}
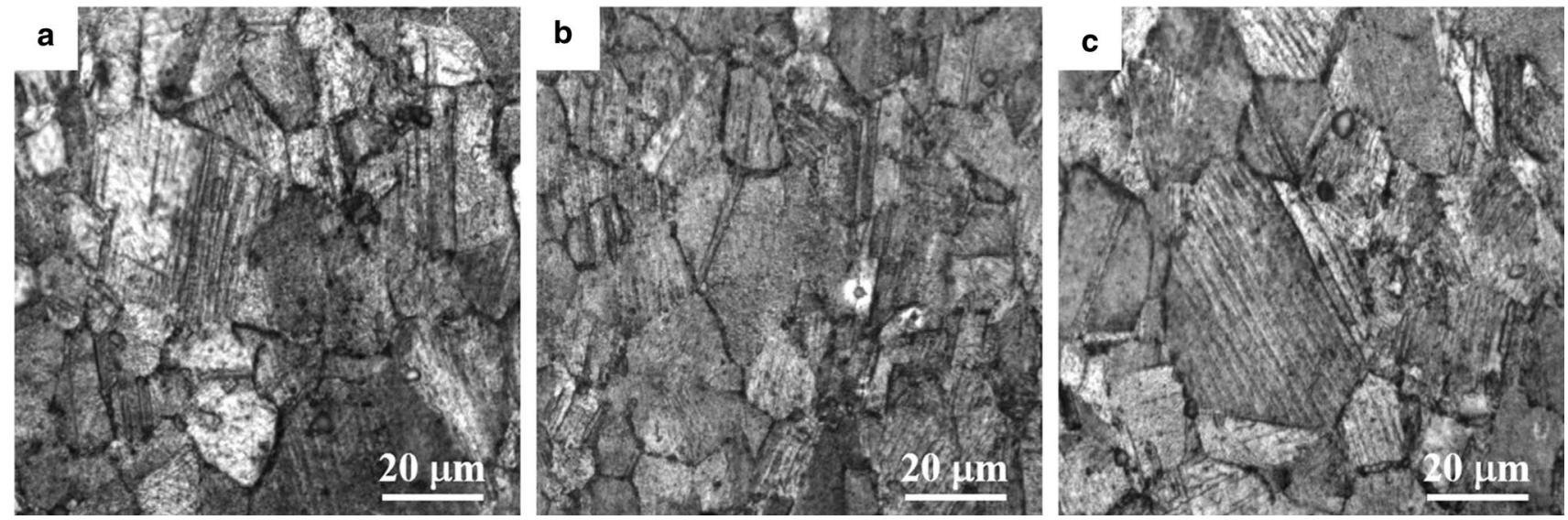

Fig. 1 Typical OM microstructures of the 15-15Ti SS samples: a R1; b R2; c R3 


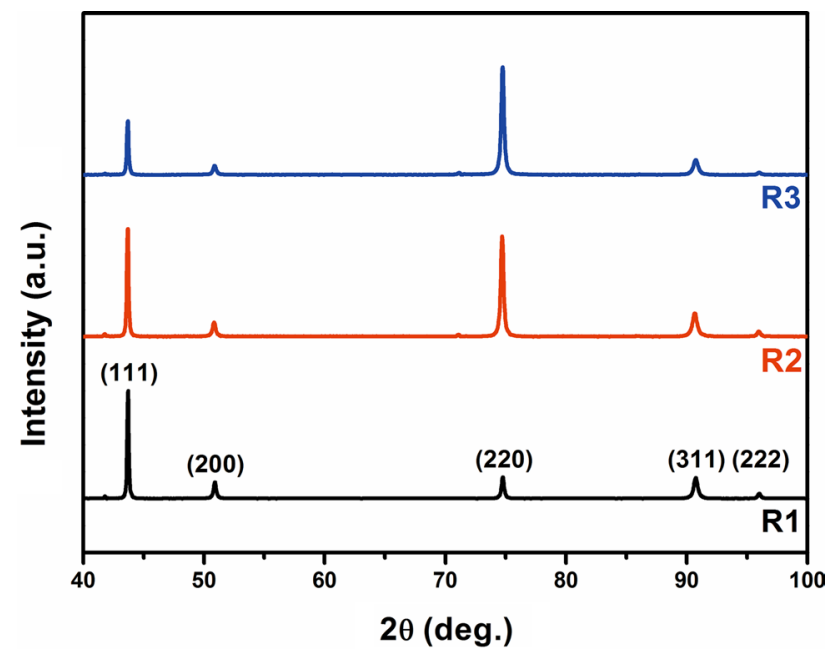

Fig. 2 Typical XRD profiles of the 15-15Ti SS samples

Table 2 XRD characterization results of steels investigated

\begin{tabular}{lrll}
\hline & $D(\mathrm{~nm})$ & $\varepsilon$ & $b(\mathrm{~nm})$ \\
\hline $\mathrm{R} 1$ & 113.3 & 0.254112 & 0.25 \\
$\mathrm{R} 2$ & 103.8 & 0.197435 & 0.25 \\
$\mathrm{R} 3$ & 85.4 & 0.170405 & 0.25 \\
\hline
\end{tabular}

the reliability of the statistical results. Volume fractions of the deformation twins in R1, R2 and R3 are determined to be $8.9 \pm 3.1 \%, 10.3 \pm 2.7 \%$ and $11.5 \pm 2.8 \%$, respectively.

\subsubsection{XRD Characterization of the Cold-Worked 15-15Ti SS}

Quantitative XRD analyses in Fig. 2 reveal a single austenitic phase matrix without any martensite for all the coldworked 15-15Ti SS samples. The dislocation densities of all the samples were determined by analyzing the XRD patterns via Rietveld software, Materials Analysis Using Diffraction [8]. The value of dislocation density $\rho$ can be calculated as follows [9]:

$\rho=3 \sqrt{2 \pi} \varepsilon^{2} \frac{1}{2} / D b$,

where $D$ is the crystallite size, $\varepsilon^{2} \frac{1}{2}$ is the microstrain and $b$ is the length of the Burgers vector. The values of above physical parameters are listed in Table 2, and the estimated dislocation densities for $\mathrm{R} 1, \mathrm{R} 2$ and $\mathrm{R} 3$ are $4.36 \times 10^{14} \mathrm{~m}^{-2}$, $5.13 \times 10^{14} \mathrm{~m}^{-2}$ and $5.48 \times 10^{14} \mathrm{~m}^{-2}$, respectively.

\subsubsection{SEM Characterization of the Cold-Worked 15-15Ti SS}

Figure 3 shows longitudinal SEM observations on the coldworked samples. Numerous small white particles, proved to be TiC by TEM observations, are distributed inside the grains. By using secondary electron imaging technique, the TiC particles are clear and distinguishable. Statistical analysis on the SEM images taken from random fields under a magnification of $5000 \times$ reveals that the volume fraction of TiC particles is almost identical for the three investigated steels. However, increment in the silicon content evidently elevates the size of precipitated particle. Specifically, the average particle size is similar for R1 and R2 ( $233 \mathrm{~nm}$ for R1 and $234 \mathrm{~nm}$ for R2) and rises to $269 \mathrm{~nm}$ for R3.

\subsubsection{TEM Characterization of the Cold-Worked 15-15Ti SS}

TEM observations reveal that the microstructures of the 15-15Ti SS samples are also rather similar in many aspects, i.e., deformation twin lamella, second-phase particle (SPP) and dislocation structure. As shown in Fig. $4 \mathrm{a}-\mathrm{c}$, the twin lamellae exhibit sharp boundaries, and the twin thickness
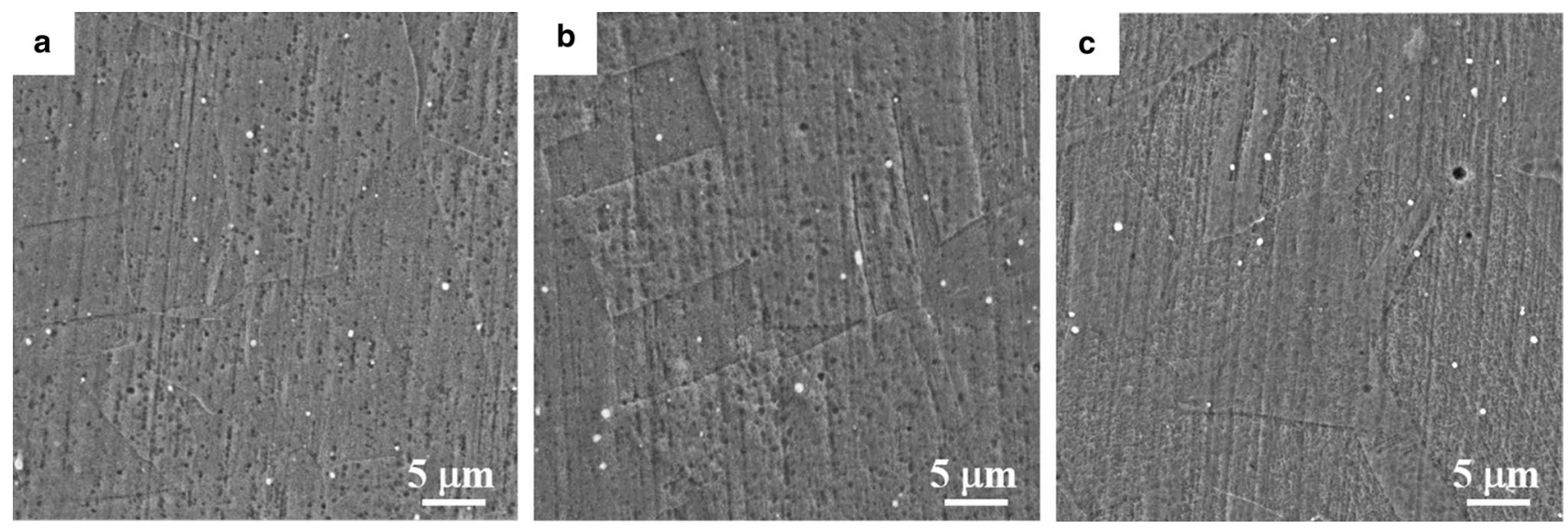

Fig. 3 Typical SEM microstructures of the 15-15Ti SS samples: a R1; b R2; $\mathbf{c}$ R3 

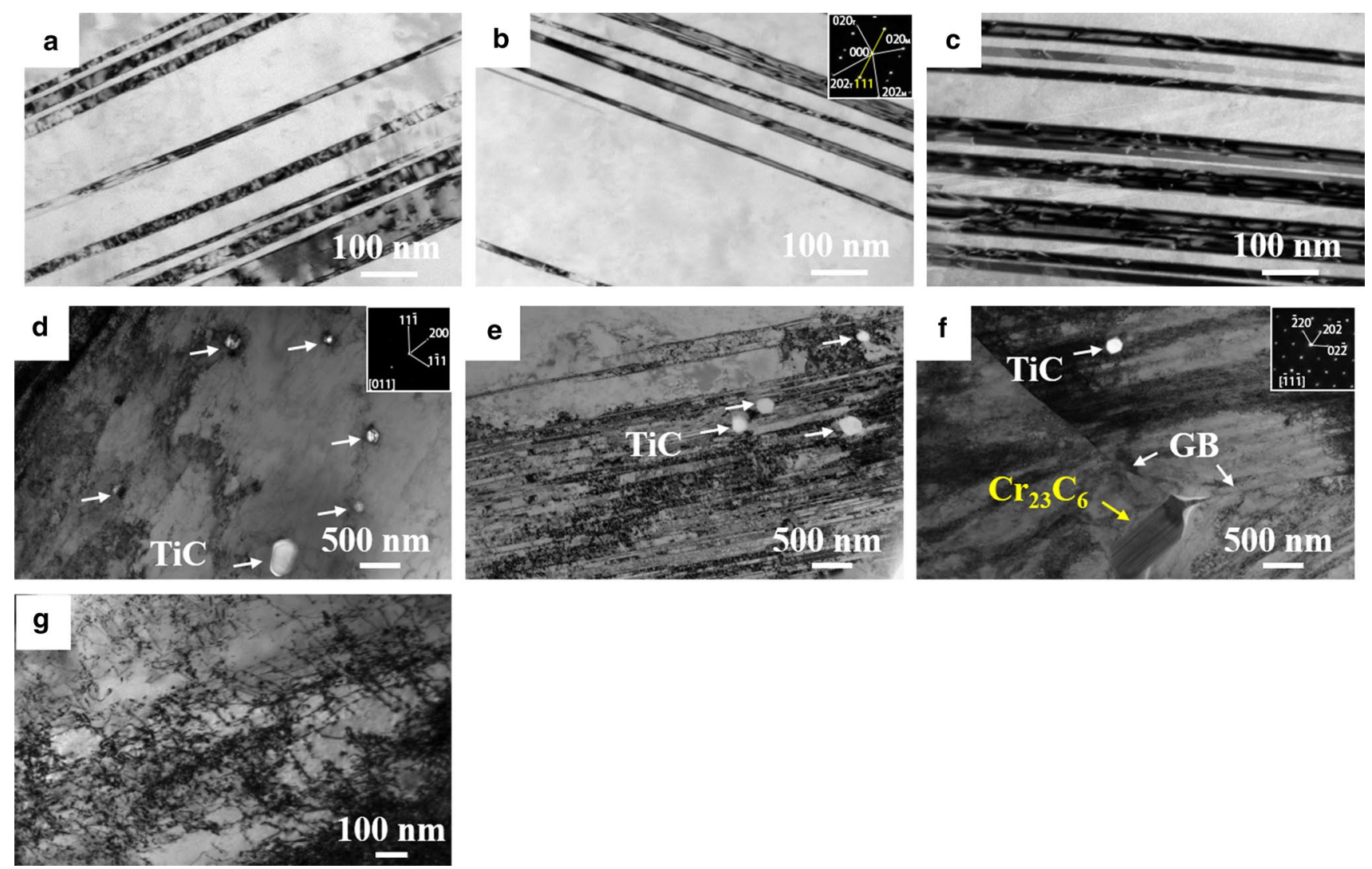

Fig. 4 Typical microstructures of the 15-15Ti SS samples: deformation twin lamella of a R1, b R2 with SAED pattern (inset) and $\mathbf{c}$ R3; TiC particles in the $\mathbf{d}$ dislocation region with SAED pattern (inset) and in the e deformation twin region of $\mathrm{R} 2 ; \mathrm{Cr}_{23} \mathrm{C}_{6}$ particle with SAED pattern (inset) on the $\mathbf{f}$ grain boundaries of R2; $\mathbf{g}$ typical dislocation structure in R3

varies from a few to $30 \mathrm{~nm}$. The average twin thickness is 8.9 $\mathrm{nm}, 10.3 \mathrm{~nm}$ and $11.5 \mathrm{~nm}$ for R1, R2 and R3, respectively.

In addition to the deformation twins, there are numerous SPPs located both inside the grains and on the grain boundaries. By using energy-dispersive spectrometry (EDS) combined with selected area electron diffraction (SAED) technique, we confirm the presence of two types of carbides, namely the $\mathrm{TiC}$ and $\mathrm{Cr}_{23} \mathrm{C}_{6}$. The $\mathrm{TiC}$ carbides mainly exist inside the grains (Fig. 4d, e), with a few occasionally observed on the grain boundaries. TiC carbides can be classified into two categories according to their sizes and morphologies. The first category is the primary carbides formed during the solidification of steel (like the largest one in Fig. 4d), which are rectangular in shape and several hundred nanometers in size. The other category is the secondary TiC carbides formed during hot work, which are globular with a size around $100 \mathrm{~nm}$. The minimum TiC particle size observed by TEM was $70 \mathrm{~nm}$.

In general, $\mathrm{Cr}_{23} \mathrm{C}_{6}$ carbides primarily precipitate on the grain boundaries. As it can be seen from Fig. $4 \mathrm{f}, \mathrm{a} \mathrm{Cr}_{23} \mathrm{C}_{6}$ particle forms at the triple junction of grains. In these investigated steels, it is strange that all the observed $\mathrm{Cr}_{23} \mathrm{C}_{6}$ carbides exhibit a stacking-fault-like microstructure under TEM, which is different from the typical TEM morphology of $\mathrm{Cr}_{23} \mathrm{C}_{6}$ carbides reported by other researchers. Nonetheless, the structural and chemical analyses by using the SAED and EDS techniques confirm that the particle indicated by a yellow arrow in Fig. $4 \mathrm{f}$ is indeed a piece of $\mathrm{Cr}_{23} \mathrm{C}_{6}$ carbide. Since the chromium content $(17 \mathrm{wt} \%)$ of all the investigated steels is relatively low, the quantity of $\mathrm{Cr}_{23} \mathrm{C}_{6}$ particles is nearly negligible compared to $\mathrm{TiC}$ particles, which is consistent with the thermodynamic calculation results in a previous study [10]. In addition, because both $\mathrm{TiC}$ and $\mathrm{Cr}_{23} \mathrm{C}_{6}$ carbides precipitate on the grain boundaries and they are quite similar in shape, it is difficult to characterize $\mathrm{Cr}_{23} \mathrm{C}_{6}$ using SEM. Besides the precipitates, typical dislocation structures in the form of tangles, walls and cells are also observed as shown in Fig. 4g.

\subsection{Tensile Properties of the Cold-Worked 15-15Ti SS}

As shown in Fig. 5, the yield strength of R3 is $682 \pm 8 \mathrm{MPa}$, $16 \mathrm{MPa}$ higher than that of $\mathrm{R} 2(666 \pm 4 \mathrm{MPa})$ and $61 \mathrm{MPa}$ higher than that of R1 $(621 \pm 10 \mathrm{MPa})$. The ultimate tensile strength of R3 $(780 \pm 14 \mathrm{MPa})$ is also higher than that of R2 $(759 \pm 6 \mathrm{MPa})$ and R1 (703 $\pm 11 \mathrm{MPa})$. However, the three 
steel samples have a nearly identical uniform elongation of about $16 \%$.

\section{Discussion}

\subsection{Effect of Silicon on the Microstructure of the Cold-Worked 15-15Ti SS}

As shown in Table 1, the only chemical composition difference among the cold-worked steel samples is the silicon content, which is $1 \%, 1.5 \%$ and $2 \%$ for $\mathrm{R} 1, \mathrm{R} 2$ and R3, respectively. In Sect. 3, one may find that deformation twins are prevalent in all the cold-worked steel samples, and no martensitic transformation occurs. Previous work has revealed that there is a deformation mechanism competition between deformation twinning and dislocation glide for the metals with medium stacking fault energy (SFE) [11]: dislocation glide dominates when SFE is above $60 \mathrm{~mJ} / \mathrm{m}^{2}$, while deformation twinning occurs when the SFE is roughly $18 \leq \gamma_{\mathrm{SFE}} \leq 60 \mathrm{~mJ} / \mathrm{m}^{2}$. In this case, the SFE of experimental steels is largely estimated to be about $60 \mathrm{~mJ} / \mathrm{m}^{2}$ by using the empirical equation proposed by Schramm et al. [12], which lies in the most sensitive SFE region for twinning. On the other hand, the SFE of austenitic steels decreases by 2.6-4

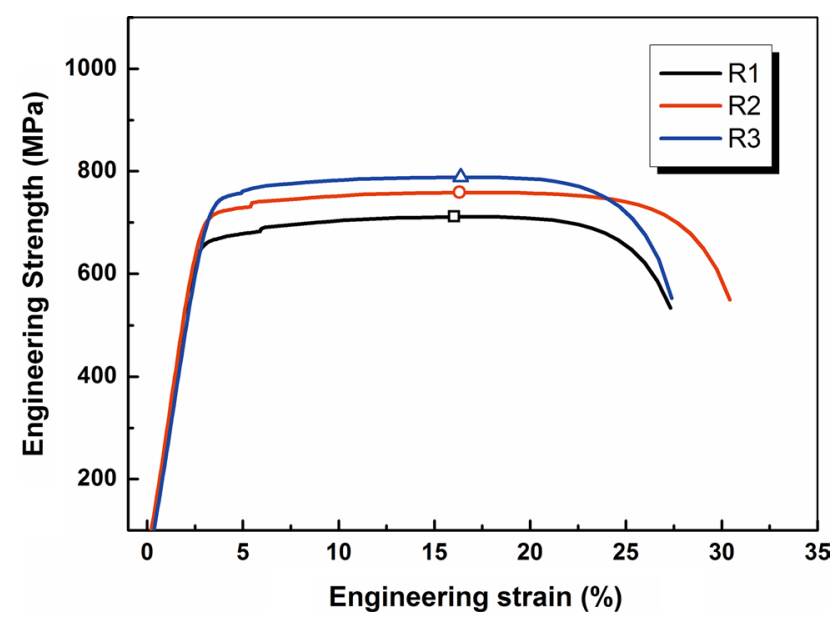

$\mathrm{mJ} / \mathrm{m}^{2}$ per $1 \mathrm{wt} \%$ silicon $[13,14]$; hence, the higher silicon contents of R2 and R3 lead to a lower SFE. Therefore, the silicon content increment from R1 to R3 generates the twin volume fraction increase and twin thickness decrease at this strain level [15].

As shown in Table 3, the average TiC particle size of R3 $(269 \mathrm{~nm})$ is higher than that of R1 $(233 \mathrm{~nm})$ and R2 (234 $\mathrm{nm})$, but the particle volume fraction is almost the same for all the samples, with the value fluctuating between 0.18 and $0.23 \%$. Bartlett et al. [16] once performed first-principles calculations and claimed that the $\mathrm{Si}-\mathrm{C}$ interaction was repulsive. Pan et al. [17] reported that silicon additions could increase the carbon activity in melt and elevate the primary precipitation temperature of MC carbide, thereby raising the size of primary MC carbides. Moreover, Ubhi and Baker [18] stated that the effect of silicon was merely accelerating the formation of MC carbides, and it had little influence on the volume fraction of precipitates. The results of the present work agree well with the literature mentioned above.

\subsection{Effects of Silicon on the Mechanical Properties of the Cold-Worked 15-15Ti SS}

Basically, strength of solution annealed steel is mainly contributed by solid solution and grain boundaries. In our case, however, the 15-15Ti SS samples have been 20\% cold worked, which contain high density of dislocations, twin boundaries and $\mathrm{TiC}$ particles. It is generally assumed that the yield strength can be combined linearly by various individual strengthening mechanisms [16]. Therefore, the relationship between yield strength and microstructure for the investigated 15-15Ti SS can be written as follows:

$\sigma_{\mathrm{y}}=\sigma_{\mathrm{SS}}+\sigma_{\mathrm{GB}}+\sigma_{\mathrm{d}}+\sigma_{\mathrm{TB}}+\sigma_{\mathrm{SPP}}$,

where $\sigma_{\mathrm{SS}}, \sigma_{\mathrm{GB}}, \sigma_{\mathrm{d}}, \sigma_{\mathrm{TB}}$ and $\sigma_{\mathrm{SPP}}$ are the strengths contributed by solid solution, grain boundaries, accumulated dislocations, deformation twins and second-phase particles (SPP), respectively.

Solid solution strengthening can be estimated by using the regression equations developed many years ago by Irvine et al. [19]:

Fig. 5 Tensile engineering stress-strain curves of the 15-15Ti SS with various silicon contents

Table 3 Microstructure characteristic parameters of steels investigated

\begin{tabular}{lllllll}
\hline Grain size $d(\mu \mathrm{m})$ & SPP size, $x(\mathrm{~nm})$ & $\begin{array}{l}\text { SPP content, } \\
f_{\text {spp }}(\text { vol } \%)\end{array}$ & $\begin{array}{l}\text { Twin thick- } \\
\text { ness, } t(\mathrm{~nm})\end{array}$ & $\begin{array}{l}\text { Twin } \\
\text { content, } f_{\mathrm{T}} \\
(\mathrm{vol} \%)\end{array}$ & $\begin{array}{l}\text { Dislocation } \\
\text { density, } \rho \\
\left(10^{14} \mathrm{~m}^{-2}\right)\end{array}$ \\
\hline $\mathrm{R} 1$ & $17.7 \pm 1.2$ & $233 \pm 13$ & $0.22 \pm 0.03$ & $11.5 \pm 4.6$ & $8.9 \pm 3.1$ & 4.36 \\
$\mathrm{R} 2$ & $17.3 \pm 1.0$ & $234 \pm 21$ & $0.18 \pm 0.03$ & $12.0 \pm 3.9$ & $10.3 \pm 2.7$ & 5.13 \\
$\mathrm{R} 3$ & $20.9 \pm 1.5$ & $269 \pm 33$ & $0.23 \pm 0.04$ & $10.0 \pm 3.2$ & $11.5 \pm 2.8$ & 5.48 \\
\hline
\end{tabular}


$\sigma_{\mathrm{SS}}=0.044+23[\mathrm{C}]+1.3[\mathrm{Si}]+0.24[\mathrm{Cr}]-0.94[\mathrm{Mo}]+1.7[\mathrm{Ti}] \times 1520$,

where $[X]$ is the weight percent of an alloy element dissolving in the stainless steel. Due to the precipitation of TiC particles in the matrix, however, the free contents of carbon and titanium in the stainless steel samples are different from the nominal contents listed in Table 1 . The theoretical density of $\mathrm{TiC}$ is $4.944 \mathrm{~g} / \mathrm{cm}^{3}$; hence, the weight percent of precipitated carbon and titanium can be calculated as follows:

$\Delta[\mathrm{C}]=f_{\mathrm{SPP}} \times \frac{4.944}{7.8} \times \frac{12}{12+48}$,

$\Delta[\mathrm{Ti}]=f_{\mathrm{SPP}} \times \frac{4.944}{7.8} \times \frac{48}{12+48}$,

where $f_{\text {SPP }}$ is the content of precipitated TiC particles. Therefore, the free carbon and titanium contents of the three steel samples are corrected, as listed in Table 4.

Consequently, the solid solution strengthening of 15-15Ti SS rises from $144 \mathrm{MPa}$ for $\mathrm{R} 1$ to $164 \mathrm{MPa}$ for R3, which is mainly caused by the ferrite-forming element silicon [13].

Grain boundary strengthening can be described by the well-known Hall-Petch equation:

$\sigma_{\mathrm{GB}}=k d^{-\frac{1}{2}}$

where $d$ is the average grain size (as listed in Table 3) and $k$ is a constant. In our case, a $k$ value of $535 \mathrm{MPa} / \mu \mathrm{m}^{1 / 2}$, obtained from Schino et al. [20] for AISI 304 SS, is used. Since the grain size of investigated steels is nearly the same, grain boundary strengthening varies slightly from $117 \mathrm{MPa}$ for R3 to $129 \mathrm{MPa}$ for R2.

The strengthening caused by dislocations can be expressed as follows [21]:

$\sigma_{\mathrm{d}}=M \alpha \mu b \sqrt{\rho}$,

where $M$ is the average Taylor factor, $\alpha$ is a constant dependent on the crystal structure, $b$ is the burgers vector of a dislocation, $\mu$ is the shear modulus and $\rho$ is the dislocation density. The values of above physical parameters for $15-15 \mathrm{Ti}$ SS are listed in Table 5, and the dislocation density is listed in Table 3. Therefore, the results of $\sigma_{\mathrm{d}}$ calculated by Eq. (7) are 277, 300 and $310 \mathrm{MPa}$ for R1, R2 and R3, respectively.

Table 4 Free contents of carbon and titanium of steels investigated (wt\%)

\begin{tabular}{lll}
\hline & Free $[\mathrm{C}]$ & Free $[\mathrm{Ti}]$ \\
\hline R1 & 0.032 & 0.25 \\
R2 & 0.037 & 0.27 \\
R3 & 0.031 & 0.24 \\
\hline
\end{tabular}

Additionally, previous studies [23, 24] on the work hardening behavior of twinning-induced plasticity (TWIP) steel also illustrated the strengthening effect of mechanical twinning (i.e., the dynamic Hall-Petch effect). According to the plasticity model proposed by Nes [25], the twin boundary strengthening can be estimated as follows:

$\sigma_{\mathrm{TB}}=M \beta \mu b / \Lambda$,

where $\Lambda$ is the dislocation mean free path and $\beta$ is a constant. Taking twin boundaries as strong obstacles for dislocation movement, $\Lambda$ can be calculated as:

$1 / \Lambda=1 / d+1 / l$,

where $d$ is the average grain size and $l$ is the mean spacing of mechanical twin lamellae, which can be linked to the twin volume fraction $f_{\mathrm{T}}$ and twin thickness $t$ as follows [22]:

$1 / l=1 / 2 t \cdot f_{\mathrm{T}} /\left(1-f_{\mathrm{T}}\right)$.

Calculating from the data in Table 3 and using a $\beta$ value of 0.24 [26], the twin boundary strengthening for R1, R 2 and $\mathrm{R} 3$ is determined to be 53,59 and $80 \mathrm{MPa}$, respectively.

As revealed in Sect. 3.1, SPPs in the investigated 15-15Ti SS are mainly incoherent TiC particles. Hence, the classic Ashby-Orowan model can be used to calculate the strengthening of SPP as follows [27]:

$\sigma_{\mathrm{SPP}}=\cdot \ln \left(x / 2.5 \times 10^{-4}\right)$,

where $f_{\mathrm{SPP}}$ is the volume fraction of TiC particles and $x$ is their mean diameter in micron. Calculating from the data in Table 3, the strengthening caused by TiC particles is only 7-8 MPa, which hardly contributes the overall yield strength.

The calculated values of the five different strengthening are summarized in Table 6, which reveals the contribution of these strengthening mechanisms to the overall yield strength. As shown in Fig. 6, the yield strength of the investigated steels is mainly contributed by the solid solution, grain boundary and dislocation strengthening. Contrarily, the SPP strengthening is negligible due to the large particle size and small volume fraction. Twinning strengthening effect is moderate due to the limited volume fraction of deformation twins at this strain level.

When the silicon content increases from 1 to $1.5 \%$ for R1 and R2, the solid solution strengthening of silicon contributes

Table 5 Values of some physical parameters for $15-15 \mathrm{Ti}$ steel [22]

\begin{tabular}{llll}
\hline$M$ & $\alpha$ & $b(\mathrm{~nm})$ & $\mu(\mathrm{GPa})$ \\
\hline 3 & 0.26 & 0.25 & 68 \\
\hline
\end{tabular}


Table 6 Experimental and calculated strengths of the investigated steels (MPa)

\begin{tabular}{llllllll}
\hline & $\sigma_{\mathrm{SS}}$ & $\sigma_{\mathrm{GB}}$ & $\sigma_{\mathrm{d}}$ & $\sigma_{\mathrm{TB}}$ & $\sigma_{\mathrm{SPP}}$ & $\sigma_{\text {cal }}$ & $\sigma_{\mathrm{y}}$ \\
\hline R1 & 144 & 127 & 279 & 53 & 8 & 611 & 621 \\
R2 & 157 & 129 & 302 & 59 & 7 & 654 & 666 \\
R3 & 164 & 117 & 313 & 80 & 7 & 681 & 682 \\
\hline
\end{tabular}

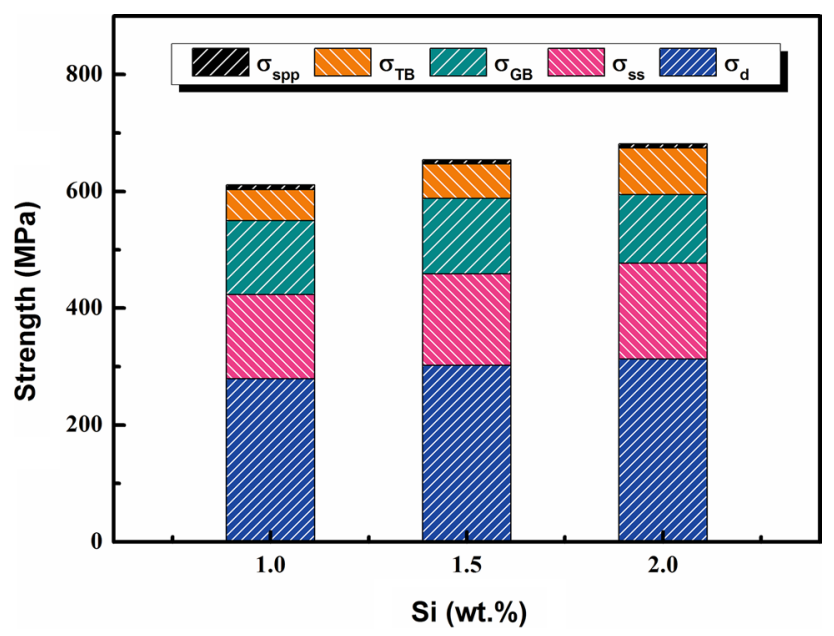

Fig. 6 Contributions of solid solution, grain boundary, dislocation, twin boundary and SPP to the yield strengths of the three 15-15Ti SS samples

$13 \mathrm{MPa}$ to the overall $45 \mathrm{MPa}$ strength increase. Meanwhile, the dislocation density increases from $4.36 \times 10^{14} \mathrm{~m}^{-2}$ to $5.13 \times 10^{14} \mathrm{~m}^{-2}$, which results in a $23 \mathrm{MPa}$ strength variation. Additionally, the volume fraction of twin lamella increases from 8.9 to $10.3 \%$ owing to the SFE reduction caused by the silicon content increment. Therefore, the twin boundary strengthening contributes $6 \mathrm{MPa}$ strength increase, which is rather weak compared to the solid solution strengthening and dislocation strengthening. The trend is similar comparing the results of R2 and R3 with $1.5 \%$ and $2 \%$ silicon, respectively. However, since the grain size of $\mathrm{R} 3$ is $\sim 4 \mu \mathrm{m}$ larger than that of R2, the grain boundary strengthening for R3 is $\sim 10 \mathrm{MPa}$ smaller. Additionally, there is little difference in dislocation density between these two samples and thus in dislocation strengthening. As a result, although the investigated samples have a constant silicon content difference of $0.5 \mathrm{wt} \%$, the yield strength difference between R2 and R3 is only $16 \mathrm{MPa}$, which is $29 \mathrm{MPa}$ smaller than that between R1 and R2.

As discussed above, silicon addition always results in an increase in the solid solution strength for austenitic steels because of its ferrite-forming element strengthening effect. On the other hand, the SFE of austenitic steels decreases with increasing silicon content, which makes cross-slip more difficult, and hence leads to a higher dislocation density, i.e., a higher dislocation strengthening effect. In addition, the reduction of SFE also promotes deformation twin formation

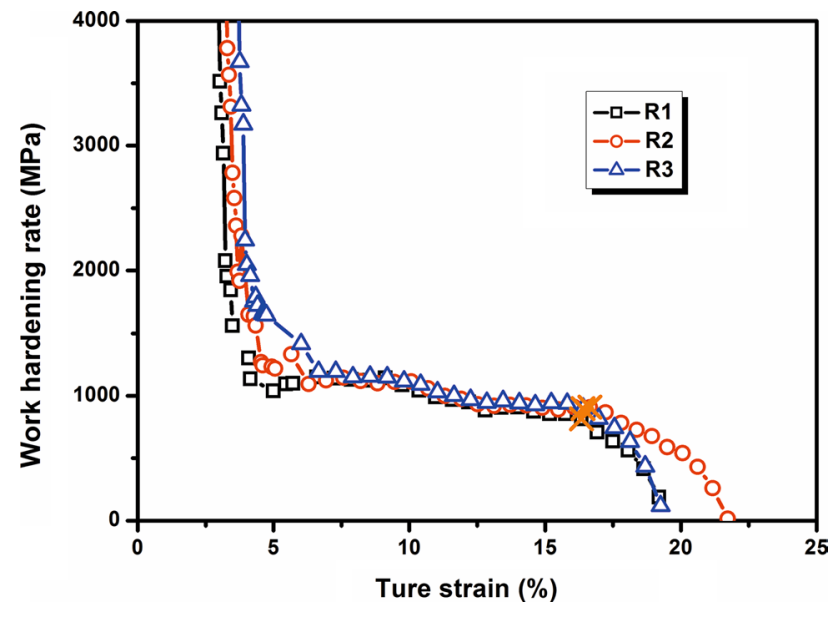

Fig. 7 Work hardening rate $\Theta$ versus true strain curves for the 15-15Ti SS samples with various silicon contents. The cross indicates the uniform elongation for the samples

and reduces twin thickness. Therefore, the twin boundary strengthening effect of 15-15Ti SS is also improved by silicon addition.

Figure 7 reveals that the work hardening behavior of the three 15-15Ti SS samples is very similar. According to Bouaziz and Guelton [28], dislocation density evolution of the alloys with TWIP effect can be expressed as follows:

$\mathrm{d} \rho / \mathrm{d} \gamma_{\mathrm{g}}=1 / b \cdot\left(\frac{1}{d}+1 / 2 t \cdot f_{\mathrm{T}} /\left(1-f_{\mathrm{T}}\right)+m \cdot \sqrt{\rho}\right)-f \cdot \rho$,

where $\gamma_{\mathrm{g}}$ is shear strain by dislocation gliding, $m=0.011$ and $f=3$ are two constants. In the process of calculation, one may find that the work hardening component $1 / 2 t \cdot f_{\mathrm{T}} /\left(1-f_{\mathrm{T}}\right)$ is one order of magnitude larger than the other two, which means TWIP effect dominates the work hardening behavior. However, the difference in twin thickness and volume fraction for the investigated steels is too small as far as considering work hardening; hence, the work hardening rate of R3 is slightly higher than the other two. Meanwhile, the strength of R3 is also slightly higher, according to the necking onset criterion:

$\Theta=\mathrm{d} \sigma / \mathrm{d} \varepsilon=\sigma$.

It is reasonable that these three samples have an identical elongation of $16 \%$. 


\section{Conclusions}

1 Both deformation twin volume fraction and dislocation density increase with silicon content for the coldworked 15-15Ti SSs, while the twin thickness slightly decreases.

2 Yield strength of 20\% cold-worked 15-15Ti SSs rises with silicon content, because of the solid solution strengthening effect of silicon and the promoted dislocation and twinning strengthening of the steels.

3 Yield strength of the 15-15Ti SSs is mainly contributed by the solid solution, dislocation and grain size strengthening effects.

4 Uniform elongation of 20\% cold-worked 15-15Ti SSs is insensitive to silicon content because of the identical work hardening behavior of the investigated steels in this work.

Acknowledgements This work is financially supported by the Natural Science Foundation of Liaoning Province, China (Grant No. 2019-BS-248).

Authors' contribution H-YY was involved in writing-original draft preparation; MW was involved in writing - review and editing; TL contributed to methodology; X-DZ contributed to investigation; Y-CM was involved in validation; and KL was involved in supervision.

\section{References}

[1] J.L. Séran, V. Levy, P. Dubuisson, D. Gilbon, A. Maillard, A. Fissolo, H. Touron, R. Cauvin, A. Chalony, E. Le Boulbin, 15th Int. Symp. ASTM STP. 1125, 1209 (1992)

[2] S. Xu, X.Q. Wu, E.H. Han, W. Ke, Y. Katada, Mater. Sci. Eng. A 490, 16 (2008)
[3] K. RamReddy, E.N. Kumar, R. Jeyaraam, G.D. Janaki Ram, V. Subramanya Sarma, Mater. Charact. 142, 115 (2018)

[4] C. Schroer, O. Wedemeyer, J. Novotny, A. Skrypnik, J. Konys, Corros. Sci. 84, 113 (2014)

[5] S.J. Zinkle, J.T. Busby, Mater. Today 12, 12 (2009)

[6] Y. Kurata, M. Futakawa, J. Nucl. Mater. 325, 217 (2004)

[7] F.A. Garner, T. Lauritzen, M.A. Mitchell, 16th Int. Symp. ASTM STP. 1175, 803 (1993)

[8] P. Sahu, M. De, S. Kajiwara, Mater. Sci. Eng. A 333, 10 (2002)

[9] R.E. Smallman, K.H. Westmacott, Philos. Mag. 2, 669 (1957)

[10] H.Y. Yi, S.H. Chen, M. Wang, T. Liang, Y.C. Ma, Chin. J. Eng. (2019). https://doi.org/10.13374/j.issn2095-9389.2019.02.24.003

[11] A.S. Hamada, L.P. Karjalainen, M.C. Somani, Mater. Sci. Eng. A 467, 114 (2007)

[12] R.E. Schramm, R.P. Reed, Metal. Trans. A 6, 1345 (1975)

[13] K. Jeong, J.E. Jin, Y.S. Jung, S. Kang, Y.K. Lee, Acta Mater. 61, 3399 (2013)

[14] G.R. Lehnhoff, K.O. Findley, B.C. Cooman, Scr. Mater. 92, 19 (2004)

[15] Y. Zhang, N.R. Tao, K. Lu, Scr. Mater. 60, 211 (2009)

[16] L.N. Bartlett, D.C.V. Aken, J. Medvedeva, D. Isheim, N.I. Medvedeva, K. Song, Metal. Mater. Trans. A 2421, 45 (2014)

[17] F.S. Pan, M. Hirohashi, Y. Lu, P.D. Ding, A.T. Tang, D.V. Edmonds, Metal. Mater. Trans. A 2757, 35 (2004)

[18] H.S. Ubhi, T.N. Baker, Mater. Sci. Eng. A 189, 111 (1989)

[19] K.J. Irvine, T. Gladman, F.B. Pickering, J. Iron, Steel Inst. 207, 1017 (1969)

[20] A. Schino, I. Salvatori, J.M. Kenny, J. Mater. Sci. 37, 4561 (2002)

[21] B. Hutchinson, N. Ridley, Scr. Mater. 55, 299 (2006)

[22] S. Allain, J.P. Chateau, O. Bouaziz, Mater. Sci. Eng. A 387, 143 (2004)

[23] O. Bouaziz, N. Guelton, Mater. Sci. Eng. A 319, 246 (2001)

[24] I. Gutierrez-Urrutia, D. Raabe, Acta Mater. 59, 6449 (2011)

[25] E. Nes, Prog. Mater. Sci. 41, 129 (1998)

[26] G. Dini, R. Ueji, A. Najafizadeh, S.M. Monir-Vaghefi, Mater. Sci. Eng. A 527, 2759 (2010)

[27] T. Gladman, D. Dulieu, I.D. Mcivor, in Proceedings of Symposium on Microalloy 75, Union Carbide Corp, New York, vol. 32 (1976)

[28] O. Bouaziz, N. Guelton, Modelling of TWIP effect on work-hardening. Mater. Sci. Eng. A 319-321, 246 (2001) 